\title{
CLÁSSICOS CONTEÚDOS DE CARTILHAS SECULARES AINDA REMEMORADOS EM LIVRO SOCIOCONSTRUTIVISTA
}

\author{
Zeneide Paiva Pereira Vieira* \\ Cláudio Eduardo Félix dos Santos*
}

\begin{abstract}
RESUMO: Este artigo tem como objetivo analisar algumas atividades do livro didático ALP: Alfabetização: Análise, Linguagem e Pensamento - Um trabalho de Linguagem numa proposta socioconstrutivista, editado após a década de 1990. Buscando atender as orientações divulgadas pelos pressupostos socioconstrutivistas para o ensino da leitura e da escrita, nos primeiros anos de escolaridade e, atendendo a grande campanha realizada pelos órgãos oficiais e pelos estudiosos do assunto, para o não-uso da cartilha como recurso norteador e da silabação como o processo de alfabetização, seus autores sugerem, no manual, muitas atividades que, de fato, rompem com a tradicional estruturação silábica. Contudo, como apresentaremos no corpo desse texto, algumas das atividades sugeridas lembram (e muito!) as propostas difundidas nos velhos manuais que subsidiaram a ação pedagógica do professor alfabetizador, ao longo da história da educação.
\end{abstract}

PALAVRAS-CHAVE: Alfabetização; Cartilha; Letramento

\section{Introdução}

A cartilha, vista como primeiro livro didático no processo de escolarização, foi tomada ao longo dos séculos como imprescindível para ensinar a ler e escrever, no processo de alfabetização. Cagliari (1998) nos informa que as cartilhas surgiram com o Renascimento

\footnotetext{
* Doutora em Memória: Linguagem e Sociedade-UESB. Professora do Departamento de Estudos Linguísticos e Literários-DELL/UESB.

** Doutor em Educação. Professor do Programa de Pós-Graduação em Memória: Linguagem e Sociedade-UESB e do Departamento de Filosofia e Ciências Humanas-DFCH/UESB.
} 
(séculos XV e XVI), época em que se inicia o uso da imprensa na Europa. Antes disso, os professores confeccionavam as Cartas do $A B C$ e as Cartas de Nomes para todos os alunos e recorriam aos comerciantes ou até mesmo aos cartórios para comprar o que denominavam de Cartas de Fora, ou seja, os autos antigos ou documentos manuscritos por escrivães os quais os alunos deveriam decifrar.

O termo Cartilha constitui, portanto, um desdobramento da palavra "cartinha", diminutivo de "carta", que historicamente tem sido um recurso didático indispensável em sala de aula, espaço, por excelência, destinado à transmissão de um saber socializado, por um professor também, historicamente legitimado para essa tarefa de ensinar a ler e escrever. Esses pequenos livros que reuniam o abecedário e o silabário traziam também como recurso, para as primeiras leituras, textos do catecismo, pois, associado ao processo de escolarização, estava a meta da colonização, propósito empreendido pelos jesuítas.

A primeira cartilha que subsidiou o trabalho do professor em nossas terras foi a de João de Barros, publicada em 1540, e que está formatada no modelo das cartinhas. Nela, o método sintético já se apresentava como o orientador do processo de ensino que iniciava com o aprendizado do alfabeto bipartido em vogais e consoantes para em seguida apresentar os ditongos, as famílias silábicas, as sentenças e os textos com propósito doutrinador, visto que além de ensinar a ler e escrever o objetivo era muito mais catequizar os meninos que viviam na colônia.

Esse modelo perpetua pela história da alfabetização e embasa a criação de muitas outras cartilhas que são adotadas, oficialmente, ao longo dos séculos, até os anos de 1990. Estes manuais buscaram orientar, passo a passo, o processo de alfabetização iniciando as lições das mais simples para as mais complexas, acreditando que todos os alunos teriam o mesmo aproveitamento na aprendizagem da leitura e da escrita.

Após a década de 1990, sob a influência da psicologia construtivista e da psicolinguística, o ensino da leitura baseado no treino das habilidades de "codificação" e "decodificação" apoiado nessas cartilhas que privilegiavam a memorização de sílabas, palavras e frases soltas, passa a ser duramente criticado pelos textos acadêmicos, pelos documentos oficiais e pelos investigadores de vários campos de estudo. Os currículos nacionais e os 
materiais pedagógicos produzidos pelo Ministério da Educação para a formação de professores, passaram a dar lugar de destaque aos estudos sobre a psicogênese da língua escrita e a defenderem que as crianças aprendessem interagindo com textos escritos, ou seja, era preciso gerar um ensino centrado "em práticas que promovessem a reflexão sobre como funciona o Sistema de Escrita Alfabética (SEA) e nas quais os aprendizes se apropriassem da linguagem convencional dos diferentes gêneros textuais escritos" (ALBUQUERQUE, MORAIS, FERREIRA, 2008, p. 253).

Nesse novo contexto, as cartilhas tornam-se objetos de estudos e questionamentos para muitos pesquisadores na área de alfabetização, os quais começam a divulgar a "ineficiência" desse material didático para a formação do leitor. De instrumento norteador do processo de ensino por toda uma história de educação, a cartilha começa, a partir desses estudos de final do século XX, a ser apontada como uma das causas do fracasso da alfabetização. Novos livros didáticos destinados ao ensino da leitura e escrita começam a ser editados, na tentativa de trazer um rico repertório textual com leituras de gêneros escritos variados em substituição às antigas atividades de pura associação fonema-grafema.

Contudo, ao estudarmos sobre a estruturação permanente de algumas cartilhas adotadas ao longo dos séculos, percebemos que uma estruturação padrão tem permanecido nesses textos destinados a alfabetizar ${ }^{1}$. E, mesmo que as cartilhas ditas construtivistas busquem romper com o modelo tradicional da silabação e traga para os alunos uma maior diversidades de gêneros textuais baseando-se numa teoria do letramento bastante difundida no final do século XX, ainda é possível verificar que resquícios da "velha" metodologia pode ser rememorada nesses novos compêndios.

Neste artigo, apresento algumas atividades destacadas do livro ALP: Alfabetização: Análise, Linguagem e Pensamento - Um trabalho de Linguagem numa proposta socioconstrutivista, edi-

\footnotetext{
1 Trabalho realizado como tese de doutorado junto ao Programa de Pós-Graduação em Memória; Linguagem e Sociedade, da Universidade Estadual do Sudoeste da Bahia, Brasil.
} 
tado após a década de 1990, para corroborar com a nossa hipótese de que a estrutura "cartilhada", presente em cartilhas antigas, não deixou de ser utilizada como norteadora da ação de alfabetizar.

\section{ALP: Alfabetização: Análise, Linguagem e Pensamento - Um trabalho de Lingua- gem numa proposta socioconstrutivista}

O livro ALP: Alfabetização: Análise, Linguagem e Pensamento, escrito por Maria Fernandes Cócco² e Marco Antonio Hailer³ ${ }^{3}$, publicado pela Editora FTD, na década de 1990, defende um aprendizado numa perspectiva socioconstrutivista. De imediato ele é adotado em algumas escolas por fugir da tradição de ensino apresentada pelas cartilhas divulgadas ao longo destes séculos, o tradicional aprendizado partindo das vogais, consoantes, sílabas, palavras, sentenças para depois o texto. Os autores apostam num trabalho centrado em diversos gêneros textuais que circulam na sociedade, os quais deverão ser lidos e analisados pelos alunos com a ajuda do professor que, paulatinamente irá inserindo estes aprendizes no mundo da leitura e da escrita. Pelo que se observa nas atividades propostas, este aprendizado acontecerá por meio de atividades interativas e lúdicas.

Ao invés de dividir o alfabeto em letras e agrupar as consoantes conforme a ordem do "mais fácil para o mais difícil", os autores apresentam "unidades temáticas", organizadas em partes. Estas, por sua vez, são compostas de um texto principal em diferentes gêneros textuais tais como poesia, pinturas, jogos, músicas, etc., seguido de atividades de interpretação textual, a serem realizadas oralmente pelo aprendiz e pelo colega.

\footnotetext{
${ }^{2}$ Licenciada em Letras e Pedagogia pela USP, com especialização e Ensino de Línguas em Buenos Aires e Madrid. Desenvolve projeto de pesquisa na área de Linguagem e presta assessoria a instituições educacionais públicas e particulares, em vários estados do Brasil.

${ }^{3}$ Bacharelado em Música e Licenciatura em Educação Artística pelo Instituto Musical de São Paulo, com especialização em Psicologia Histórico-Cultural pela Universidade Complutense de Madrid. Atua como consultor educacional de Secretarias Municipais de Educação, em São Paulo e no Paraná.
} 
O primeiro tema intitulado "A Escola" é apresentado como "Introdução" e objetiva trabalhar atividades que favoreçam a adaptação da criança na escola, incluindo o trabalho com os nomes dos colegas e a sua convivência com o grupo;

Na primeira parte, o tema é "Ver e ouvir" cujo propósito é a reflexão sobre o significado da escrita e da vinculação entre fala e escrita. As atividades propostas giram em torno da leitura de gravuras compondo "história" de criança indo para a escola e desenvolvendo atividades escolares; do uso do crachá com o nome da criança; desenho de objetos que existem na sala de aula e cópia do nome de um dos objetos desenhados na classe, conforme se lê em Cócco; Hailer (1990, p. 9): "Sua professora vai escrever na lousa o nome dos objetos que vocês desenharam. Copie o nome de um objeto".

$\mathrm{Na}$ segunda parte a ênfase é o aprendizado do código lingüístico a partir do trabalho com os nomes dos alunos e diferentes atividades com o alfabeto, por isso a composição desta parte em três unidades: "O nome da gente"; "Tudo pode ser escrito" e "O nome das coisas".

A terceira parte apresenta diferentes unidades temáticas: "Os animais"; "Brincar, jogar e aprender"; "Receitas para crescer" e "Lugares diferentes". A grande investida aqui é a construção da base alfabética da escrita, conforme registra os autores nas "Anotações para os professores" (p.33) "Espera-se que durante a realização das propostas, a maioria da classe vá conquistando a escrita alfabética de palavras e frases".

A quarta parte se encerra em uma única unidade "Hora de dormir" cuja proposta é um trabalho mais ampliado em relação ao alfabeto quando o aluno deverá aprender todos os tipos de letra: imprensa e cursiva nos formatos maiúscula e minúscula. Para isso, destaca os autores em "anotações para o professor” (p.33) “(...) que não há necessidade de fazer treinos exaustivos e cópias de letras e nem usar o caderno de caligrafia. Mas há a necessidade de mostrar o traçado correto das letras e a união delas em palavras e frases". Vê-se, assim, uma ruptura com a aplicação de atividades de prontidão que eram consideradas imprescindíveis para se aprender a ler e escrever. 
Para finalizar, tem-se a quinta parte do livro com as unidades temáticas "Festas"; "Histórias Fantásticas" e "A natureza”. Aqui, pelo que se lê nas orientações ao professor, Cócco e Hailer (1995, p. 33) propõem "a escrita de textos alfabéticos em letra cursiva e o desenvolvimento de leitura silenciosa e em voz alta, com compreensão”.

Cada uma dessas unidades temáticas busca colocar na ação pedagógica um novo conceito de alfabetização que se contrapõe à mera codificação e decodificação fonemagrafema dos “textos cartilhados”. A preocupação deste novo manual didático é propor uma alfabetização na perspectiva do letramento que defende o aprendizado da leitura e da escrita a partir do uso real destas e, partindo desse pressuposto, seus autores, Cócco e Hailer (1995, p. 32) apresentam uma estrutura de trabalho que vai compor cada uma dessas unidades a qual apresento a seguir:

Figura 1- Estrrutura do ALP

\section{ESTRUTURA DO LIVRO ALP — ALFABETIZAÇÃO}

0 livro ALP - ALFABETIZAÇÃO tem como centro de trabalho os textos diversificados, explorados, a partir dos seguintes aspectos:

1. LENDO - compreende atividades de observação, tentativa de decodificação, decodificação propriamente dita, leitura em voz alta e leitura silenciosa.

2. CONVERSANDO - questōes de conteúdo, estrutura e análise do discurso dos textos, desenvolvidas oralmente pelo professor $\mathrm{e}$ alunos.

3. DESCOBRINDO - compreende o trabalho de interpretação escrita, presente a partir da Unidade IX, envolvendo questões de conteúdo, estrutura e alguns aspectos da análise do discurso.

4. PENSANDO E CONSTRUINDO - atividades, jogos e propostas variadas, cujo objetivo é a aquisição do VSC (Valor Sonoro Convencional) e da reconstrução do código lingüistico, utilizando letras, palavras, frases e textos, com todos os tipos de letras.

5. ESCREVENDO - atividades variadas e jogos, propondo a produção de palavras, frases e textos, utilizando letra de fôrma maiúscula (até a Unidade VII) e letra cursiva (a partir da Unidade IX).

6. ATIVIDADEDE ENRIQUECIMENTO - propostas de ampliação de vocabulário e extrapolação, desenvolvidas, principalmente, através de jogos e atividades de linguagem extraverbal.

7. MEU JEITO DE ESCREVER - sondagem de palavras e frases (até a Unidade VII), e de textos (a partir da Unidade IX), cujo objetivo é ajudar o professor a acompanhar o desenvolvimento das concepções lingüisticas das crianças. Há uma parte deste manual dedicada à explicação do desenvolvimento desta atividade (ver pág.13). Não se deve considerar a sondagem uma verificação, mas esta deve servir como instrumento de adequação e projeção do trabalho a ser desenvolvido.

Fonte CÓCCO; HAILER, 1995, p. 32

Seguindo as estruturas acima, o professor alfabetizador, que antes encontrava nas cartilhas, letras e sílabas, deverá, com este novo livro, alfabetizar numa outra perspectiva, isto é, numa concepção em que o aprendizado se fará a partir das unidades globais da língua 
- palavras ou textos -, conforme ilustraremos abaixo ao explicitarmos as atividades propostas para o ensino da leitura e da escrita.

Tomemos como exemplo a Unidade 1 com o tema "Ver e ouvir". Logo de início, no primeiro ponto da estruturação - "Lendo" - o aluno toma contato com uma gravura "Na Rua” e a proposição para "ler" o que está escrito.

Figura 2- Leitura de Gravura, no ALP

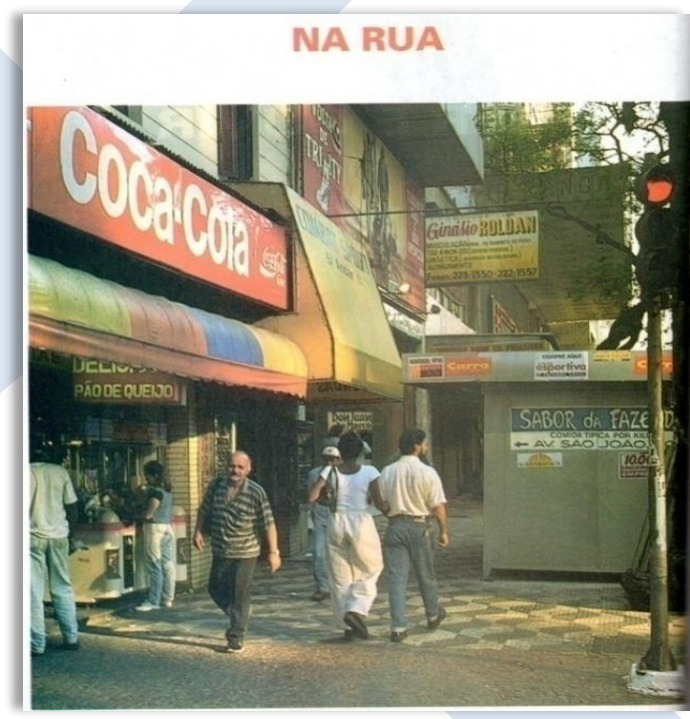

Fonte CÓCCO; HAILER, 1995, p. 14

Ler gravuras?! Eis já uma primeira e grande ruptura em relação ao método tradicional das antigas cartilhas. Naquelas, a gravura aparecia junto à letra para tornar possível com mais facilidade a sua memorização; a primeira lição trazia as cinco vogais e os encontros vocálicos para serem lidos e memorizados pelos alunos. Aqui, o aluno já depara, na primeira lição, com uma gravura como sinônimo de texto que deve ser lido com a ajuda de um professor que, por muitos anos alfabetizou tendo em mão a cartilha tradicional e, muito provavelmente, não compreende o como e o porquê trabalhar com textos. Essa leitura está 
vinculada à percepção que o aluno fará do que aparece escrito na paisagem; do que está registrado com letras e do que pode ser visto pelo aluno no seu dia-a-dia, ou seja, na rua onde ele transita, inclusive no percurso casa-escola, portanto, uma "leitura" vinculada às práticas sociais do aprendiz.

Muda-se a concepção de leitura; a criança agora é vista como alguém que lê o mundo que a cerca muito antes de aprender sistematicamente a leitura e a escrita e essa leitura tem agora importância para a escola que a realiza como uma atividade que irá contribuir para o desenvolvimento do educando.

No segundo ponto da estruturação desse texto - "Conversando" - os autores apresentam questões que devem ser discutidas oralmente com os alunos acerca da gravura apresentada para leitura; o objetivo aqui é desenvolver a expressividade do aluno, o que também podemos considerar uma ruptura uma vez que o aluno que antes aprendia com a cartilha tradicional e só podia repetir as sílabas apresentadas, agora pode expressar a sua opinião falando de si e escutando o outro. Vejamos:

Figura 3- Atividade oral, no ALP

\section{Conversando}

1. Para que servem as coisas escritas que aparecem na foto?

2. A cena da foto acontece de dia ou de noite? Como você percebeu?

3. Você conhece um lugar parecido com o da foto? Onde fica?

4. Se você estivesse na foto, onde gostaria de estar? O que gostaria de estar fazendo?

5. Como é a rua onde você mora?

Fonte CÓCCO; HAILER, 1995, p. 15

Em seguida o aluno é convidado a "ler" e "escrever" não mais letras isoladas como o professor estava acostumado a ensinar pelas "velhas" cartilhas, mas escrever palavras e frases como se vê na atividade a seguir: 
Figura 4 - Atividde de escrita, no ALP

\section{Escreverico}

1. Você vai fazer um passeio com sua professora e ler TUDO o que estiver escrito: cartazes, placas, nomes de lojas, nomes de ruas, propagandas etc.

Depois, com a ajuda da professora, escreva no espaço abaixo as palavras e frases que vocês encontraram.

No item "Pensando e Construindo", o aluno é convidado a expressar-se do seu jeito:

Figura 5- Atividade extraescolar, no ALP

\section{Penstando e constitindo}

Faça um passeio pela sua escola. Observe bem o que existe nela e desenhe:

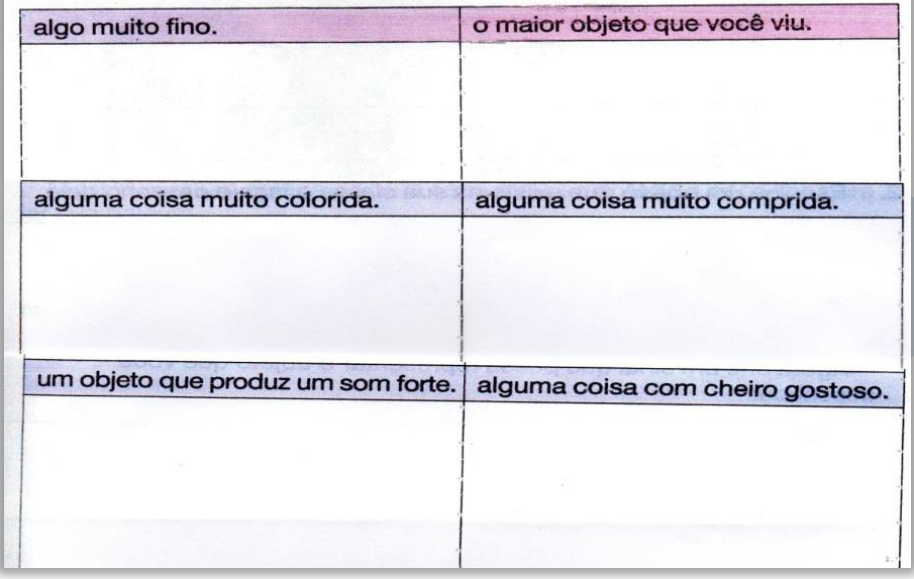

Fonte CÓCCO; HAILER, 1995, p. 16 
Aqui, considera-se que o aprendizado também se dá fora da sala de aula, por toda a escola, e defende-se que cada aluno poderá ver coisas diferentes do ambiente a ser explorado. Ampliam-se os espaços de leitura, os tipos de suporte, os usos sociais dos textos que passam a ser lidos e discutidos em situações autênticas de leitura compartilhada pela via da leitura oralizada de outrem, professora e alunos que já dominam a decifração do código escrito.

Destaca-se assim, a necessidade da interação entre os alunos quando se sugere que os desenhos dos alunos sejam socializados entre os colegas da classe e de uma classe "mais adiantada" que deverá ler o que foi registrado, por já ter o domínio do código escrito, conforme atividade proposta por Cócco; Hailer (1990, p. 19). O ensino, desse modo, está alicerçado na participação ativa das crianças e na troca de conhecimentos entre elas e o professor. Observe a atividade:

Figura 6- Atividade de interação, no ALP

Mostre para um colega de uma série mais adiantada e peça-Ihe para ler sua palavra.

Por que você acha que ele conseguiu ler?

Fale o nome de seu desenho e observe as letras que são usadas para escrevê-lo.

Recorte de revistas as letras que formam a palavra que representa o seu desenho e cole aqui.

Fonte CÓCCO; HAILER, 1995, p. 19

A partir desse momento, o aluno começa a aprender letras do alfabeto mas, não mais um alfabeto seqüenciado com as letras de A a Z; os autores apresentam uma poesia que destaca algumas palavras iniciadas com as letras A, D e F. 
Figura 7 - Atividade com letras, no ALP

QUAL É A LETRA?

Ruth Rocha

A é a letra de AVIĀo, de Amarelo E DE ATENÇÃO. DE Automóvel

E AsSombraçÃo...

COM A LETRA D Se escreve Dedo. COM A LETRA D Se escreve Dado. COM A LETRA D SE ESCREVE:

DIA, DOR,

Dragão e Delegado.

F e a letra de Folia, Flor, Fanfarra, Fantasia. É a letra de Futebol,
Farofa, Fera, Farinha, Farelo, Filho, Folhinha. de Fantasma e de Farol...

Palavras, muitas palavras... São Paulo, Quinteto Editorial, 1985.

Fonte CÓCCO; HAILER, 1995, p. 21

Partindo do pressuposto de que o aluno ainda não lê o referido texto, os autores sugerem que "A professora vai ler o texto" para depois continuar com o aluno na realização das atividades do "Descobrindo", "Escrevendo" e as "Atividades de enriquecimento", como se vê abaixo: 
Figura 8 - Atividade relacionadas ao texto, no ALP
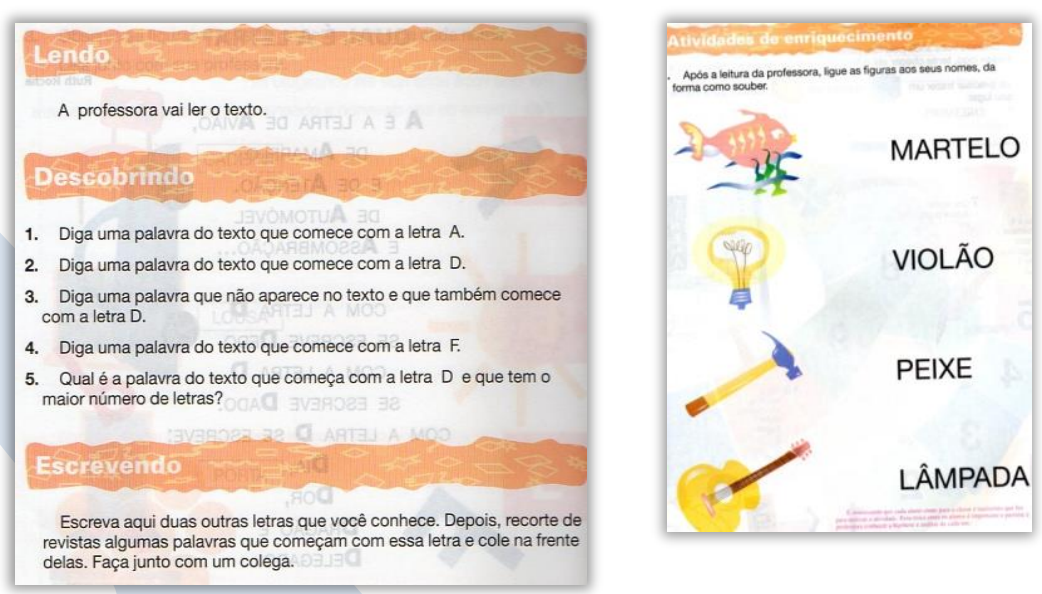

Fonte CÓCCO; HAILER, 1995, p. 22-23

Finalizando a "lição", o aluno deverá escrever do seu jeito:

Figura 9 - Atividade de escrita, no ALP

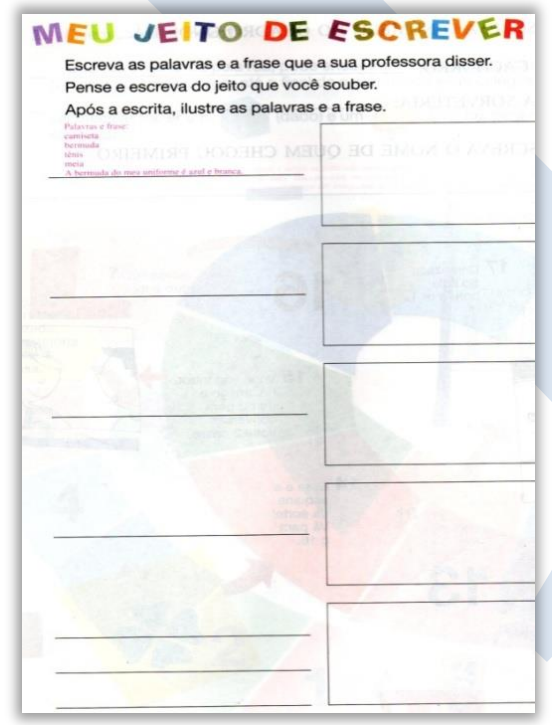

Fonte CÓCCO; HAILER, 1995, p. 12 


\section{Atividades estruturadas numa perspectiva do letramento ainda remontam as lem-} branças de um velho passado de alfabetização

Tomando o nosso foco de pesquisa a qual objetivou a analisar o livro - ALP destinado para alfabetizar e o que nele tem permanecido como memória alfabetizadora, verificamos que este "novo" livro, lançado em plena efervescência do construtivismo, do combate aos métodos tradicionais de ensino da leitura e escrita, traz com muita evidência um distanciamento do texto cartilhado, portanto, de um ensino sistematizado de escrita alfabética que sequencialmente inicia-se pela vogais, consoantes, sílabas, palavras, frases e, por fim, o texto. Defendendo os fundamentos socioconstrutivistas da linguagem, os autores apresentam um leque de textos variados, de gêneros distintos com diferentes atividades que possibilitem ao aluno uma aproximação com a cultura escrita.

Pelo que analisamos, há que se reconhecer uma ruptura com relação à estrutura canônica das "velhas" cartilhas, pois como vimos não temos a linearidade de letras-fonemassentenças-textos que subsidiou o trabalho do professor, ao longo dos séculos. Contudo, pelo que também analisamos, algumas estruturas, mesmo que ressignificadas para um contexto de interação e construção do conhecimento, trazem à tona lembranças de atividades já vistas em cartilhas utilizadas por professores em décadas ou séculos anteriores. Tomamos para exemplificar tal constatação, o ensino do alfabeto.

Quando nos detemos a analisar o alfabeto exposto no referido livro, remetemo-nos à formatação semelhante já exposta nas Cartas do $A B C$, no século XVII. Observamos que o traçado das letras permanece nos quatro alfabetos a ser aprendidos pelos alfabetizandos. A ruptura em relação ao trabalho proposto no "velho" manual é que aquele trazia a bipartição vogais/consoantes, própria do método silábico, o que não se lê no ALP, uma vez que este se apresenta ao professor alfabetizador como um livro que "desconstrói" o método "tradicional" utilizado para alfabetizar ao longo dos séculos. Comparemos: 
Figura 10 - Comparação do Alfabeto, do ALP e das Cartas do ABC

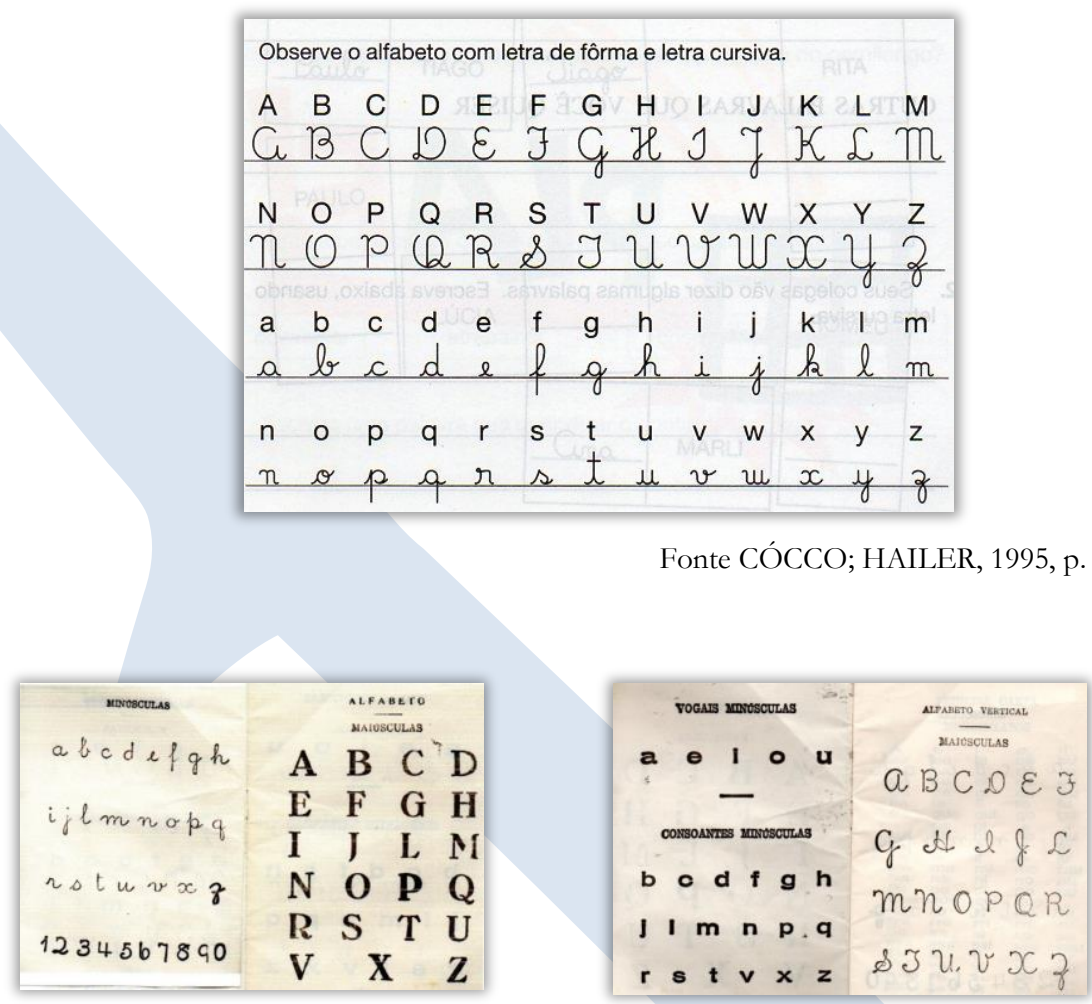

Fonte: Método ABC, impresso pela Caderbrás, Ind. Brasileira (s/d, p. 1-4)

Nos anos de 1830 também já podíamos ler, no final do Método de Castilho, o alfabeto completo, sem bipartição vogais/consoantes, nas quatro modalidades de letras, como o que acontece no ALP, livro editado nos anos de 1990. 
Figura 11- Alfabetos no Método Castilho
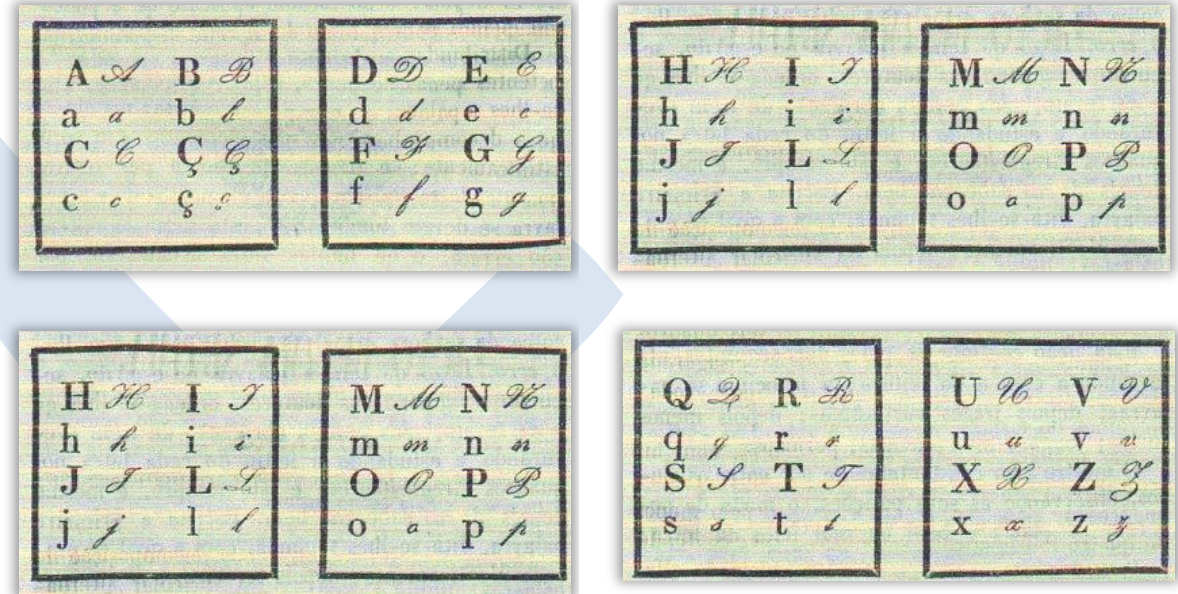

Fonte: Castilho, 1853, p. 268

Outras atividades com as letras do alfabeto, em muito nos fazem rememorar atividades já apresentadas em cartilhas dos séculos XVI e XVIII, conforme destacaremos abaixo:

1. A poesia Será que você sabe ler? nos remete aos contos utilizados por Castilho para destacar cada letra do alfabeto, vejamos:

Figura 12 - Atividade com Letras, no ALP e no Método Castilho

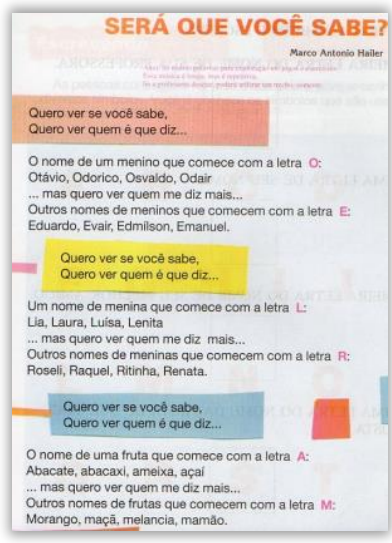

Fonte: CÓCCO; HAILER, 1995, p. 46

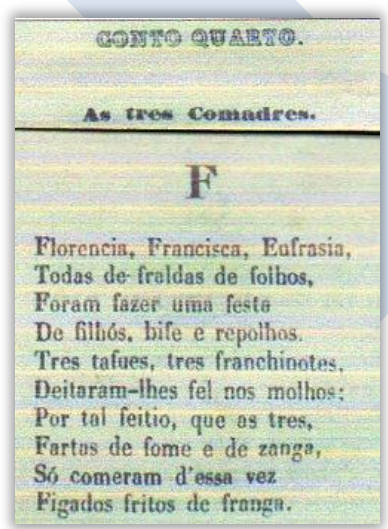

Fonte: Castilho, 1853, p. 219 
2. A atividade de construção de um alfabeto ilustrado proposta no ALP, muito embora busque superar as atividades de leitura e escrita mecânicas das letras apresentadas nas cartilhas adotadas pelos professores tecnicistas, se assemelham à ideia de ilustração proposta na Cartinha de João de Barros, adotada no século XVI. Aquele autor utilizava-se da figura para facilitar a memorização das letras que eram aprendidas já no início do processo. Cócco, autora da ALP, por sua vez, não traz em seu livro a sequência alfabética, mas também acata a relação letra/gravura como estratégia importante para conhecimento do alfabeto. Observemos:

Figura 13 - Atividade com Letras, no ALP e na Cartinha de João de Barros

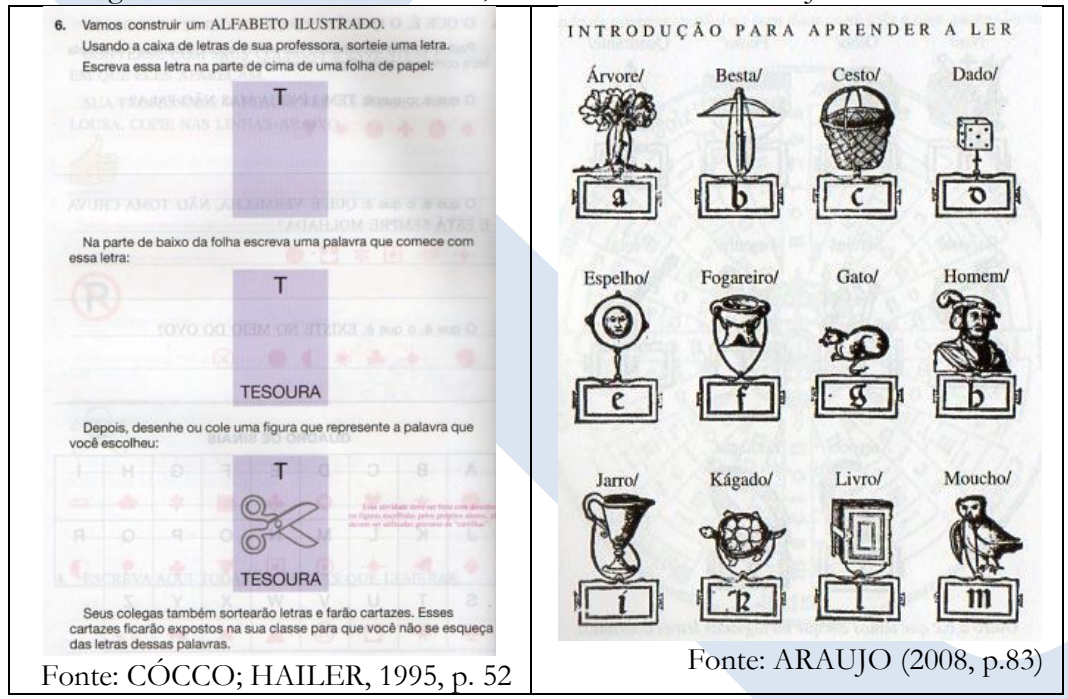

Outra atividade que nos faz rememorar princípios defendidos por autores do passado é o que Cócco; Hailer (1995) denominam de "Atividades de Enriquecimento", um exercício de caráter lúdico proposto ao final de cada unidade temática que compõe o livro ALP. Para esses autores, "por meio do jogo, do fazer, do brincar, do representar, a criança experimenta 'ir além', ultrapassa seus próprios limites, adquirindo autonomia na aprendizagem" (p.13). Como exemplo, destacamos uma atividade relacionada ao aprendizado de letras do alfabeto, logo nas primeiras lições do livro: 
Figura 14 - Atividade lúdica, no ALP

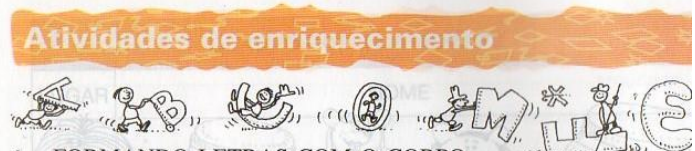

1. FORMANDO LETRAS COM O CORPO.

Forme um grupo de 5 a 6 colegas. Quando for dado o sinal combinado, montem, usando os próprios corpos, a letra indicada.

Depois, diga uma palavra que começa com a letra formada por seu grupo.

ESCREVA ESSA PALAVRA.

Fonte: CÓCCO; HAILER, 1995, p.58

De modo similar, Castilho também, defendendo o princípio de liberdade e ludicidade, registrou ao final de cada lição do seu método uma proposição de trabalho denominada de "Divertimentos". Eram atividades de jogos, desenhos, pinturas; momentos em que a aprendizagem estaria associada a "óras de recreção", a "um bom passatempo", como se lê em Castilho (1853, p.41):

Figura 15 - Atividade lúdica, no Método Castilho

\section{DIVEATIMENTOS.}

Para as óras de recreaçào, tanto em colegios, como em easas particulares, podem-se induzir as crianęas ou a copiarem com giz em ardozia, ou com lapis em papel as fórmas das seis letras vogaes, eu mesmo a arremedarem as seis figuras de qe as letras sâo sombras.

Um bom passatempo seria ainda, avendo seis crianças, pintar-se a cada um no seu carapuço de papel uma das vogaes em ponto grande, avendo doze as grandes e pegenas; e sendo mais repetirem-se, e fazer com que eles nos seus jogos se chamassem pelos nomes das suas letras.

Fonte: Castilho, 1853, p. 41

Vale ressaltar, que tais comparações ilustram apenas o fato de que em meio às rupturas, alguns fragmentos de uma memória alfabetizadora permanecem no fazer pedagógico 
do processo alfabetizador. Não negamos: há um investimento para a mudança, nesse novo livro. Seu objetivo era alfabetizar na perspectiva da leitura e compreensão global de textos de gêneros variados como bilhete, instrução de jogos, poesia, conto de fadas, reportagem, receita, verbete de enciclopédia, trava-línguas, cartaz publicitário, notícia de jornal, etc., isto é, numa diversidade de textos que circulam na nossa sociedade. A orientação era para que o professor considerasse que, mesmo os alunos não sabendo ler e escrever, eles já possuíam conhecimentos prévios das funções da escrita e das características dos diversos gêneros textuais, como afirma Soares (1990, p. 39):

Ter-se apropriado da escrita é diferente de ter aprendido a ler e escrever: aprender a ler e escrever significa adquirir uma tecnologia, a codificar em língua escrita e de decodificar a língua escrita; apropriar-se da escrita é tornar a escrita própria, ou seja, é assumir com sua propriedade.

Esse livro foi amplamente divulgado e bastante adotado no final da década de $1990 \mathrm{em}$ muitas escolas brasileiras, substituindo as antigas cartilhas do ba-be-bi-bo-bu. Outros livros foram editados nessa mesma época, porém, pelo que temos observado na prática e pelo que temos lido do relato de outras práticas estudadas em diferentes localidades brasileiras, a exemplo de estudos realizados por Araujo (2004), esses livros destinados a alfabetizar numa perspectiva extremamente contrária à cartilha secular, não ultrapassou a década de 1990. Examinando as práticas e concepções de docentes de três cidades em Pernambuco, esta pesquisadora constatou que os professores que empregavam os novos livros de alfabetização reconheciam a qualidade do repertório textual oferecido, mas queixavam-se explicitamente da ausência, nos livros, de atividades para ensinar aos alunos a notação alfabética. Diziam que de nada servia letrar os alunos sem que aprendessem o bế-á-bá para que pudessem ler de forma efetiva e autônoma.

Do mesmo modo, Frade (2003) nos revela que a grande meta desses livros é uma quase negação da decodificação e de métodos para alfabetizar e uma grande defesa pelos textos de função social e do letramento. Ao entrevistar alfabetizadores quanto a validade desses "novos" livros, em pesquisa realizada em duas escolas públicas de Belo Horizonte, ela nos revela (p.186) que esses professores atestam ser o "novo" livro didático recebido pela escola, 
[...] melhor que o do ano anterior, porque é integrado e interdisciplinar, mas não atende à clientela, pois vem para crianças que já sabem ler, com textos grandes. É bom, mas não dá para seguir. Usase para tirar algumas atividades e mais para consulta. Segundo seu depoimento o livro didático não atende às necessidades dos alunos, apesar de ser bom. Para os alunos daqui trabalharem nele, tem que ser para as séries subsequentes. Ela se utiliza de parlendas e músicas para alfabetizar, porque avalia que o livro didático que veio para sua escola não traz essa abordagem de músicas. Complementa com xerox de atividades de outros livros, literatura, jornal, revista, letras de macarrão, jogos. Enfim, segundo ela: todas as bugigangas que um professor tem que produzir.

Para que o uso dos "novos" livros semelhantes, ao ALP, também lançados no mercado editorial "construtivista" fosse eficiente e, mais ainda, para que o professor pudesse alfabetizar numa outra concepção, diferente daquela em que ele havia sido alfabetizado ou até mesmo da que vinha alfabetizando seus alunos até a década anterior, muitos cursos foram oferecidos por muitas universidades do país, por agências formadoras, por Secretarias estaduais e municipais de educação, em praticamente todo o território brasileiro, a exemplo do que nos revela a professora, cujo depoimento, destaco da minha dissertação de mestrado (VIEIRA, 1998, p. 89 e93) e transcrevo abaixo:

Eu ainda não sei como transmitir [o construtivismo] para a criança. Por muito tempo acostumada com o tradicional, tomar lição; mudar o método sem orientação mais profunda, pois nesses cursos só dá teoria e prática, nada. Se você só sabe teoria, como vai aplicar na prática? (p.93)

\section{$[\ldots]$}

Eu estou insegura com esse método construtivista e o construtivismo pede pra ler jornal, revista, recorte de propaganda [...] foi isso que a coordenadora passou [...] se ela tivesse ido à sala e me mostrado como eu faria, mas só disse e eu fiquei insegura. Como é que eu vou passar uma coisa para o aluno se eu não sei? Eu iria deixá-lo mais inseguro e eu me preocupo muito com ele. (p.89)

A mesma insegurança tem sido revelada por professores que descartaram esses novos livros. Na realidade, eles sentiram falta de um trabalho mais sistemático voltado para o eixo da "alfabetização". Alguns docentes preferiram não usar os livros que chegaram às 
escolas e buscaram desenvolver suas práticas de alfabetização com o apoio de outros materiais e até mesmo de atividades voltadas para a silabação, conforme também comprovamos em depoimento de professora mineira, entrevistada por Frade (2005, p.55):

Utilizo muito o método silábico, por achar que o aluno aprende mais depressa, mas para fazer o diagnóstico da escrita, utilizo a teoria de Emília Ferreiro e as hipóteses que as crianças usam para construir a escrita. Mas também não deixo de trabalhar com parlendas, receitas e outros tipos de textos, lembrando um pouco o método global, apesar de minha preocupação maior ser com a decodificação. Há uma mistura, às vezes, mas o eixo principal do meu trabalho é o silábico, pois tenho mais facilidade e segurança com ele. Percebo que tenho que mudar um pouco e trabalhar mais ainda com a questão do letramento, para que as crianças entendam melhor o uso da escrita.

O depoimento dessa professora nos atesta que, mesmo com a oficialização desse modelo construtivista de alfabetização, com a edição desses "novos" livros, com o investimento e ampliação na formação dos professores numa perspectiva construtivista ou socioconstrutivista, a cartilha e os métodos tradicionais continuaram a ser amplamente utilizados, explicita ou disfarçadamente, nas classes de alfabetização em nossas escolas. Mais uma vez, a oficialização de um "novo método", via distribuição de livro didático específico não se tornou garantia para que o professor deixasse de lançar mão do já aprendido, deixasse de utilizar as atividades que sempre estiveram presentes nas cartilhas antigas, mesmo quando estas foram substituídas por livros elaborados na contramão do método da silabação.

\section{Considerações Finais}

Do exposto, mesmo diante de tantas inovações pedagógicas, podemos concluir que há uma estruturação de conteúdos alfabetizadores, própria de uma estruturação difundida pelas cartilhas, que permanece viva em algumas atividades difundidas em "novos" livros didáticos, publicados sob orientação construtivista, para alunos em fase de alfabetização.

Não é meu objetivo, nesse texto, discutir a validade ou mesmo tecer considerações sobre a eficácia ou não das atividades aqui apresentadas. O objetivo foi apresentar a permanência de atividades que vão sendo revividas em um novo livro editado para suplantar 
as velhas cartilhas e o método da silabação utilizados para alfabetizar por um longo período de escolarização em nosso país. Percebemos que, mesmo com a oficialização do discurso construtivista, a partir do inicio da década de 1990, defendendo o não-uso da cartilha secular, as poucas atividades aqui analisadas, nos refletem uma memória alfabetizadora que foi implementada nos tempos dos jesuítas e que foi sendo utilizada nos livros didáticos destinados, oficialmente, ao ensino da leitura e da escrita até os anos de 1990. Assim, como nos esclarece Jedlowski apud Sá (2005, p. 66) mesmo que o fato memorizado "nunca permaneça uno e idêntico", as atividades aqui elencadas nos fazem ver que as lembranças guardadas no inconsciente sob forma de imagens são evocadas pelo sujeito e trazidas à sua realidade. É a memória ultrapassando a mera capacidade de se reportar a fatos passados para reconstituí-los com os olhos do presente como bem situa Bosi (1993, p. 55), ao escrever que "na maior parte das vezes lembrar não é reviver, mas refazer, reconstruir, repensar, com imagens e ideias de hoje, as experiências do passado".

\title{
CLASSICAL CONTENTS OF SECULAR BOOKLETS STILL REMEMBERED IN SOCIO-CONSTRUCTIVIST BOOK
}

\begin{abstract}
This article aims to analyze some activities of LLT textbook: Literacy: Analysis, Language and Thought - A Language work in a socio - constructivist proposal, edited after the 1990s. Seeking to meet guidelines published by socio-constructivist assumptions for teaching of reading and writing, in the first years of schooling, and in view of great campaign carried out by official bodies and scholars, for non-use of book as a guiding resource and syllabic activity as literacy process, their authors suggest, in that textbook, many activities which, in fact, break with traditional syllabic structuring. However, as we will present in this text, some of the suggested activities recall (and much!) the proposals disseminated in the old manuals which have subsidized the pedagogical action of literacy teacher throughouthistory of education.
\end{abstract}

KEYWORDS: Literacy; Primer; Lettering.

\section{REFERÊNCIAS}

ALBUQUERQUE, Eliana Borges Correia de; MORAIS, Artur Gomes de; FERREIRA, Andréa Tereza Brito. As práticas cotidianas de alfabetização: o que fazem as professoras? Revista Brasileira de Educação, v. 13, n. 38, maio/ago, 2008. 
ARAÚJO, Adriana. Usar ou não usar novos livros didáticos de alfabetização: concepções e práticas dos professores ao ensinar o sistema de escrita alfabética. Dissertação (Mestrado em Educação) - Centro de Educação, Universidade Federal de Pernambuco, Recife, 2004.

ARAÚJO, Gabriel Antunes de. Apresentação. In: BARROS, João de. Cartinha com os preceitos e mandamentos da Santa Madre Igreja: 1539 ou gramática da língua portuguesa. São Paulo: Humanitas/Pulistana, 2008.

BARROS, João de. Cartinha com os preceitos e mandamentos da Santa Madre Igreja: 1539 ou gramática da língua portuguesa. São Paulo: Humanitas/Pulistana, 2008.

BOSI, Ecléa. Memória e sociedade: lembranças dos velhos. São Paulo: Companhia das Letras, 1993.

CAGLIARI, Luiz Carlos. Alfabetizando sem o bá-bé-bi-bó-bu. São Paulo: Scipione, 1998.

CASTILHO, António Feliciano de, Método Castilho para o ensino rápido e aprasivel do ler impresso, manuscrito, e numeração e do escrever. 2. Ed. Lisboa: Impr. Nacional, 1853. Disponível em: <http://purl.pt/185/5/P190.html>.

CÓCCO, Maria Fernanda; HAILER, Marco Antonio. Alp: alfabetização: análise, linguagem e pensamento: um trabalho de linguagem numa proposta socioconstrutivista. São Paulo: FTD, 1995.

FRADE, Isabel Cristina Alves da Silva. Escolha de livros de alfabetização: dialogando com permanências históricas e com modelos atuais de inovação. In: História da Educaşão, ASPHE/FAE/UFPEL, Pelotas, n 14, p. 173-193, set. 2003

FRADE, Isabel Cristina Alves da Silva. Métodos e didáticas de alfabetização: história, características e modos de fazer de professores: caderno do professor. Belo Horizonte: Ceale/FaE/UFMG, 2005.

Método $A B C$ : ensino prático para aprender a ler. Caderbrás. Indústria Brasileira. S/d.

SÁ, Celso Pereira de. (Org). Imaginário e Representações Sociais. Rio de Janeiro: Museu da República, 2005.

SOARES, Magda Becker. Alfabetização: em busca de um método? Belo Horizonte. Educação em Revista, N. 12, dez/1990.

VIEIRA, Zeneide Paiva Pereira. Leitura nas séries iniciais: práticas em busca de sentido. Dissertação de Mestrado. Universidade Federal da Bahia-UFBA, 1998.

Recebido em: 28/07/2018.

Aprovado em: 12/12/2018. 